\title{
Acute abdomen in early pregnancy caused by torsion of bilateral huge multiloculated ovarian cysts
}

\section{Sathiyakala Rajendran*, Suthanthira Devi}

Department of Obstetrics \& Gynaecology, Sri Sathyasai Medical College and Research Institute, Thiruporur, Tamilnadu, India

Received: 22 August 2015

Revised: 09 September 2015

Accepted: 12 September 2015

\section{*Correspondence:}

Dr. Sathiyakala Rajendran,

E-mail: sathya_jipmer@yahoo.co.in

Copyright: $\odot$ the author(s), publisher and licensee Medip Academy. This is an open-access article distributed under the terms of the Creative Commons Attribution Non-Commercial License, which permits unrestricted non-commercial

\begin{abstract}
The association of pregnancy and torsion of bilateral huge benign ovarian cyst is rare. We report a case of multigravida at 13 weeks of pregnancy presenting with acute onset of lower abdominal pain. Ultrasound revealed bilateral multiloculated ovarian cysts of size $10 \times 10 \mathrm{~cm}$ on right side and $15 \times 10 \mathrm{~cm}$ on left side with evidence of torsion and a single live intrauterine fetus of gestational age 13 weeks 4 days. Emergency laparotomy was done with vaginal susten $200 \mathrm{mg}$ as perioperative tocolysis. Intra operatively, uterus was enlarged to 14 weeks size. Both ovaries were replaced with multiloculated cysts of size $15 \times 10 \mathrm{~cm}$ on left side and $10 \times 10 \mathrm{~cm}$ on right side. Ovarian pedicle was found to be twisted once on right side and twice on left side. On right side, untwisting of pedicle was done and the ovarian cyst was punctured at multiple sites to drain the clear fluid. Biopsy was taken from the right ovarian cyst wall. On left side, ovariotomy was done. Histopathology revealed mucinous cyst adenoma of left ovary and multiple corpus luteum in right ovarian biopsy specimen. The patient was followed up with regular antenatal check-ups and ultrasound to rule out the recurrence of ovarian cyst on right side. The patient successfully delivered a term male baby at 39 weeks.
\end{abstract}

Keywords: Torsion of bilateral ovarian cyst, Huge mucinous cyst adenoma, Acute abdomen in pregnancy, Huge ovarian cyst

\section{INTRODUCTION}

The association of pregnancy with symptomatic ovarian cyst is relatively rare. The ovarian cysts commonly found associated with pregnancy include corpus luteum cyst, dermoid cyst, endometrioma, serous cystadenoma and mucinous cystadenoma. Though the risks of malignancy in these cysts are low, there can be complications resulting from distension, haemorrhage, torsion and rupture. In this case report, we present a multigravida at gestational age of 13 weeks 4 days with torsion of bilateral huge ovarian multiloculated cysts.

\section{CASE REPORT}

A 25 year old Gravida 5 Para 2 Live 2 Abortion2 presented to the outpatient department at 13 weeks 4 days of pregnancy with acute lower abdominal pain. She had acute onset of lower abdominal pain which was felt more on left side. The pain was continuous, severe, aching in nature, no radiation, no aggravating or relieving factors and not associated with fever, nausea or vomiting. There was no increased frequency of micturition, dysuria, white discharge or bleeding per vaginum. Her physical examination revealed tachycardia, tenderness in lower abdomen with cystic mass felt in left iliac fossa. There was no guarding or rigidity. Urgent ultrasound revealed bilateral multiloculated cystic ovarian masses of size 
$15 \times 10 \mathrm{~cm}$ on left side, $10 \times 10 \mathrm{~cm}$ on right side with features suggestive of torsion on left side and also a single live intrauterine fetus of gestational age 13 weeks 4 days. Emergency laparotomy was done with vaginal Susten 200mg as perioperative tocolysis. Intraoperatively, both the ovaries were found to be replaced with multiloculated cystic masses with smooth surface, of size left side $15 \times 10 \mathrm{~cm}$ and right side $10 \times 10$ $\mathrm{cm}$. Ovarian cysts were found to be tortuous, coiled twice on left side and once on right side. As left ovarian cyst was found to be unhealthy, left ovariotomy was done. Right ovarian cyst was untwisted and punctured at multiple sites. Clear fluid was drained and the size of the right ovary was reduced to $5 \times 4 \mathrm{~cm}$.Biopsy was taken from right ovarian cyst wall. Postoperative period was uneventful. Histopathology revealed mucinous cystadenoma of left ovary and multiple corpus luteum in right ovarian cyst wall biopsy. The patient was followed up with regular antenatal visits and ultrasound to rule out recurrence of ovarian cyst on right side. The patient successfully delivered a term male baby at 39 weeks.

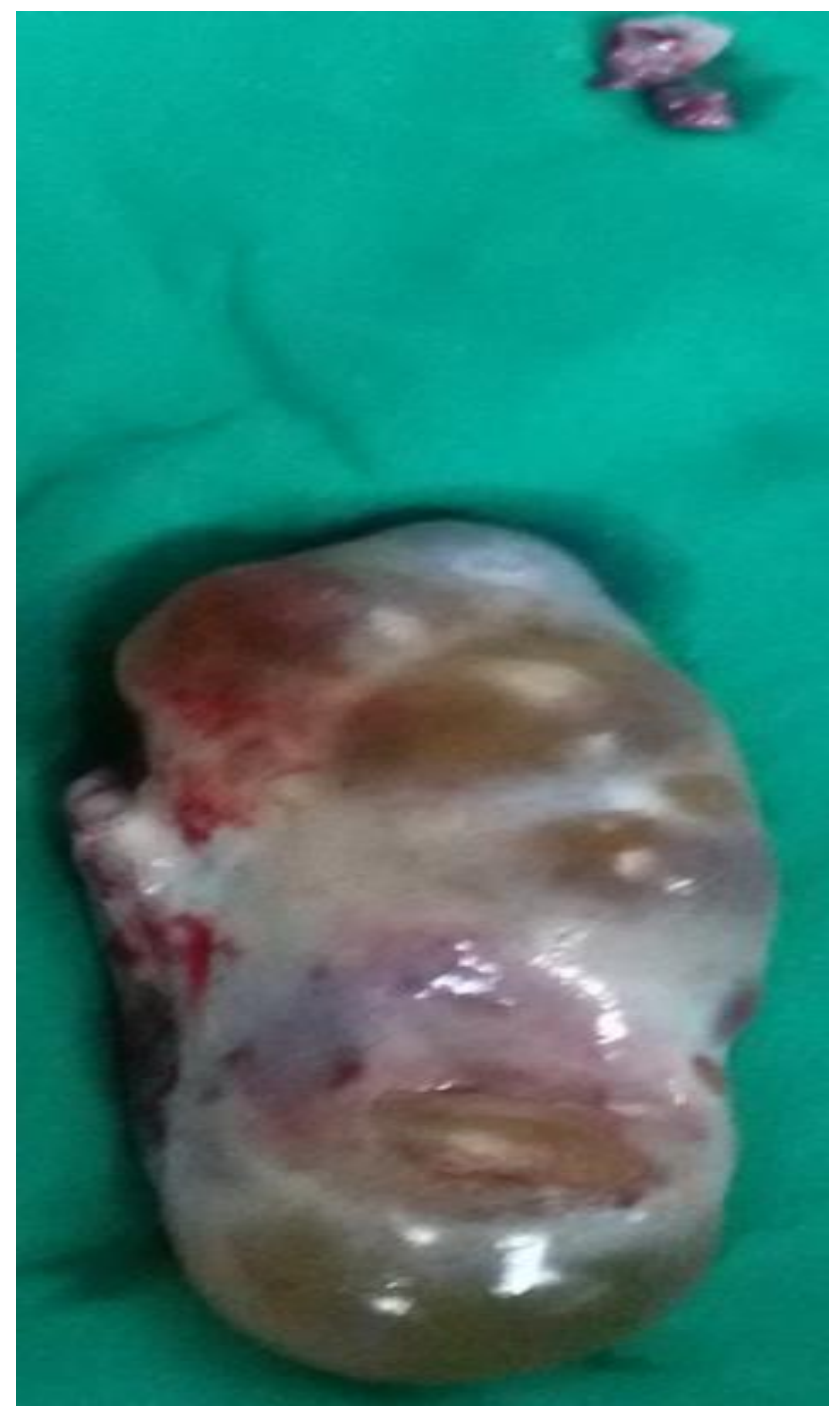

Figure 1: Multiloculated left ovarian cyst and right ovarian biopsy specimen.

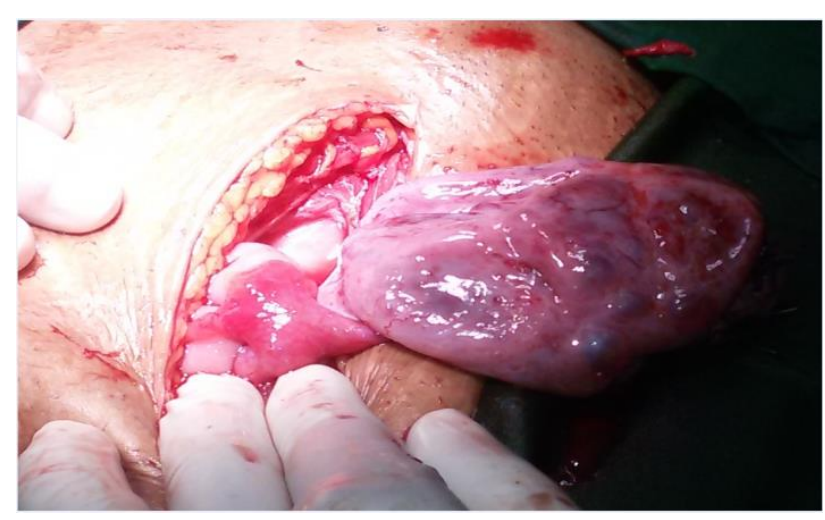

Figure 2: Right ovary - after draining fluid from the multiloculated cyst.

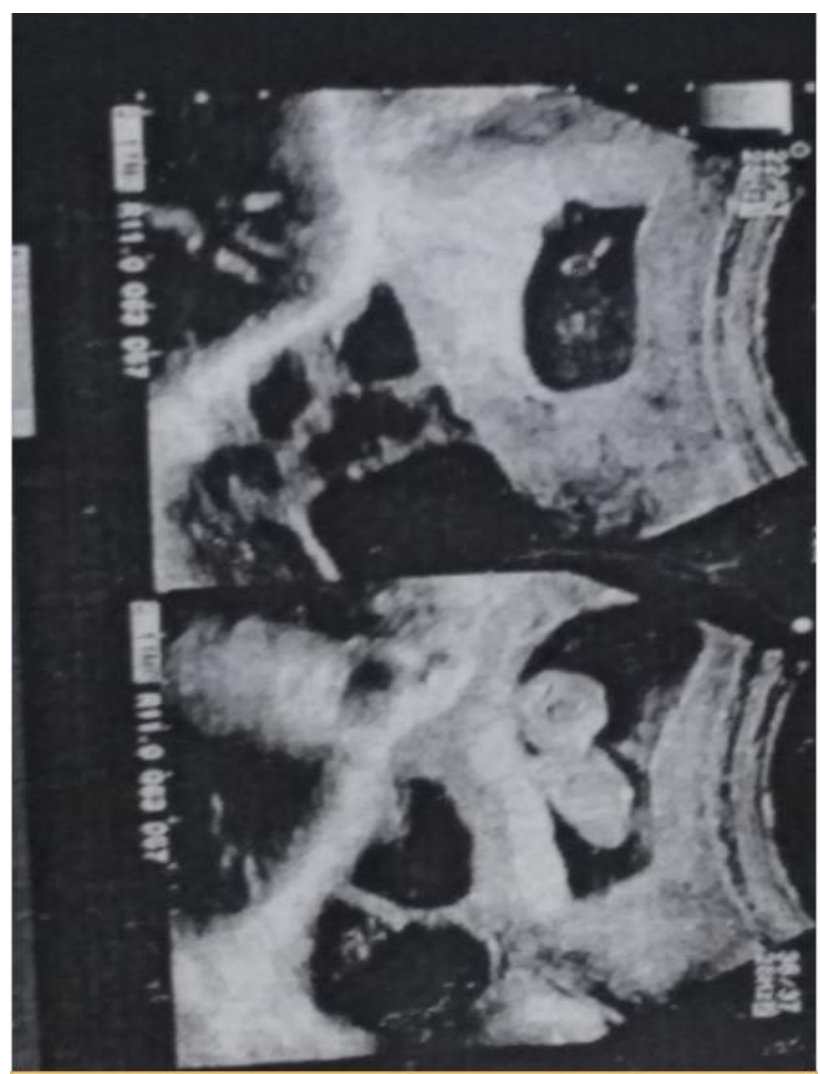

Figure 3: Ultrasound image showing single live intrauterine fetus and multiloculated cyst.

\section{DISCUSSION}

The incidence of adnexal pathology detected in first trimester varies from 0.2 to $2.9 \% .^{1,2}$ The majority of ovarian cysts $(71.9 \%)$ detected in first trimester ultrasound resolve spontaneously and hence assumed to be physiological in nature. ${ }^{3,4}$ Ovarian tumors that persist beyond 16 weeks of pregnancy are more likely to be neoplastic.

The common pregnancy associated tumors include solitary luteinized follicular cysts, hyperreaction luteinalis, corpus luteum of pregnancy, granulosa cell 
tumors, sertoli cell tumors, endometriomas, dermoid cysts, serous cystadenoma, mucinous cystadenoma and malignant tumors.

In our case, the histopathology of ovarian mass revealed mucinous cystadenoma. Mucinous cystadenoma accounts for up to $20 \%$ of all ovarian tumors. They tend to occur in middle aged women. It is rare in adolescent age group or in pregnant women. They are bilateral in $10 \%$ of cases. They may enlarge to very large size even up to $50 \mathrm{~cm}$ in diameter and may be multilocular. The outer wall is white, grey or silvery blue in colour. Microscopically, the cysts are lined by tall columnar cells which resemble that of the glands of the cervix or of the intestine. They secrete a mucus material, a glycoprotein with high content of neutral polysaccharides.

As the pregnant uterus enlarges, the tumour will be lifted into the abdominal cavity and does not interfere with either pregnancy or labour. But, sometimes complications do occur. As in our case, torsion of the pedicle of the tumour can occur during pregnancy. When the tumour gets impacted in the pelvis, it may lead to retention of urine, malpresentations or obstructed labour. Rupture of ovarian cyst can occur during pregnancy or labour. The tumour may be malignant or may become malignant during pregnancy.

The management of ovarian tumour complicating pregnancy is still controversial. The literature is reviewed to find out the optimal management of ovarian tumour complicating pregnancy.

In 2003, Stepp et al, conducted a review to assess the safety of laparoscopic treatment of adnexal masses in the second trimester of pregnancy. ${ }^{5}$ The average gestational age at the time of surgery was 17 weeks 4 days. They concluded that the laparoscopic treatment of adnexal masses in the second trimester is safe and effective but the surgeon must be skilled in advanced techniques of laparoscopic surgery.

In 2005, Schmeler et al reviewed 1, 27,177 pregnancies. $^{6}$ There was adnexal mass of size greater than $5 \mathrm{~cm}$ in 63 patients $(0.05 \%)$. They concluded that close observation is a reasonable alternative to antepartum surgery in patients with an adnexal mass during pregnancy.

In 2007, Tica et al reported a case in which unilateral twisted ovarian cyst of size $11 \mathrm{~cm}$ at 6 weeks of gestation was managed by initial conservative management and emergency laparotomy and cystectomy at 16 weeks required by the acute abdominal pain caused by the torsive cyst. $^{7}$

In 2009, Yen et al analysed 214 pregnancies with adnexal masses greater than or equal to $4 \mathrm{~cm}^{8}$ Torsion was encountered in $14.84 \%$ of patients. Adnexal masses with sizes between $6 \mathrm{~cm}$ and $8 \mathrm{~cm}$ had a significantly high risk of torsion compared with other sizes. Sixty percent of torsion happened between $10^{\text {th }}$ and $17^{\text {th }}$ weeks of gestation. Tumor diameters more than or equal to $10 \mathrm{~cm}$ at initial diagnosis had a high risk of malignancy versus smaller sizes. They concluded that adnexal tumors with high risk for torsion and malignancy should be strongly considered for an aggressive strategy of management during pregnancy.

In 2014, Goh et al analysed the recent literature and concluded that most adnexal masses in pregnancy are benign and ultrasound characteristics can help guide the assessment of asymptomatic ovarian masses, allowing expectant management of benign asymptomatic adnexal masses until delivery or postpartum. ${ }^{9}$ The review also highlights the well tolerated use of laparoscopy for the antenatal removal of suspicious or symptomatic masses and that expectant management of asymptomatic masses does not increase the risk of adverse pregnancy outcomes.

In 2014, Siew-Fei et al conducted a retrospective review of pregnant women before 20 weeks of gestation who underwent laparoscopy or laparotomy for management of an adnexal mass. ${ }^{10}$ They concluded that surgical management of adnexal masses during pregnancy appears to have favourable outcomes for the mother and the fetus. There was no significant difference in obstetric outcomes between the laparoscopy and laparotomy groups.

In 2015, de Haan et al conducted a review to decide the most appropriate treatment option for ovarian cysts or masses during pregnancy. ${ }^{11}$ They concluded that the ultrasound and MRI are safe diagnostic tools to distinguish benign and malignant lesions. Expectant management is advised for ovarian cysts with benign features. Treatment options should be discussed for each patient individually. Both open surgery and laparoscopy can be performed considering the tumor diameter, gestational age and surgical expertise. A multidisciplinary approach is necessary in case of high suspicion of malignancy.

\section{CONCLUSION}

The ovarian cysts complicating pregnancies can be diagnosed with the first trimester ultrasound. Benign and malignant ovarian cysts can be distinguished with ultrasound doppler or MRI. Asymptomatic benign ovarian cysts can be managed expectantly until delivery or postpartum. Surgical management is required for suspicious or symptomatic masses. Laparoscopy is found to be safe in first and second trimester of pregnancy, if the surgeon is competent. Laparotomy is preferred in the third trimester of pregnancy especially if the fetus is mature, so that caesarean section can be done with removal of ovarian cyst.

\section{Funding: No funding sources \\ Conflict of interest: None declared \\ Ethical approval: Not required}




\section{REFERENCES}

1. Czekierdowski A, Bednarek W, Rogowska W, Kotarski J. Difficulties in differential diagnosis of adnexal masses during pregnancy: the role of grayscale and colour doppler sonography. Ginekol Pol. 2001;72:1281-6.

2. Ballard CA. Ovarian tumors associated with pregnancy termination patients. Am J Obstet Gynecol. 1984;149:384-7.

3. Goffinet F. Ovarian cysts and pregnancy. J Gynecol Obstet Biol Reprod. 2001;30(suppl 1):S100-8.

4. Zanetta G, Mariani E, Lissoni A, Ceruti P, TrioD, Strobelt N, Mariani S. A prospective study of the role of ultrasound in the management of adnexal masses in pregnancy. BJOG. 2003;110:578-83.

5. Stepp KJ, Tulikangas PK, Goldberg JM, Attaran M, Falcone T. Laparoscopy for adnexal masses in the second trimester of pregnancy. J Am Assoc Gynecol Laparosc. 2003;10(1):55-9.

6. Schmeler KM, Mayo smith WW, Peipert JF, Weitzen $\mathrm{S}$, Manuel MD, Gordinier ME. Adnexal masses in pregnancy: surgery compared with observation. Obstet Gynecol. 2005;105:1098-103.
7. Tica VI, Tomescu A, Russu E, Beghim M, Tica I, Serbanescu L, Bafani S. Ovarian cyst and pregnancy conservative management and consecutive emergency cystectomy. Rev Med Chir Soc Med Nat Lasi. 2007;111(4):976-80.

8. Yen CF, Lin SL, Murk W, Wang CJ, Lee CL, Soong YK, Arici A. Risk analysis of torsion and malignancy for adnexal masses during pregnancy. 2009;91(5):1895-902.

9. Goh W, Bohrer J, Zalud I. Management of the adnexal mass in pregnancy. Curr Opin Obstet Gynecol. 2014;26(2):49-53.

10. Ngu SF, Cheung VYT, Pun TC. Surgical management of adnexal masses in pregnancy. JSLS. 2014;18(1):71-5.

11. de Haan J, Verheecke M, Amant F. Management of ovarian cysts and cancer in pregnancy. Facts views vis obgyn. 2015;7(1):25-31.

Cite this article as: Rajendran S, Devi S. Acute abdomen in early pregnancy caused by torsion of bilateral huge multiloculated ovarian cysts. Int J Reprod Contracept Obstet Gynecol 2015;4:1598-01. 